\title{
Per- and Polyfluoroalkyl Substances Exposure and Bone Mineral Density in the U.S. Population From NHANES 2005-2014
}

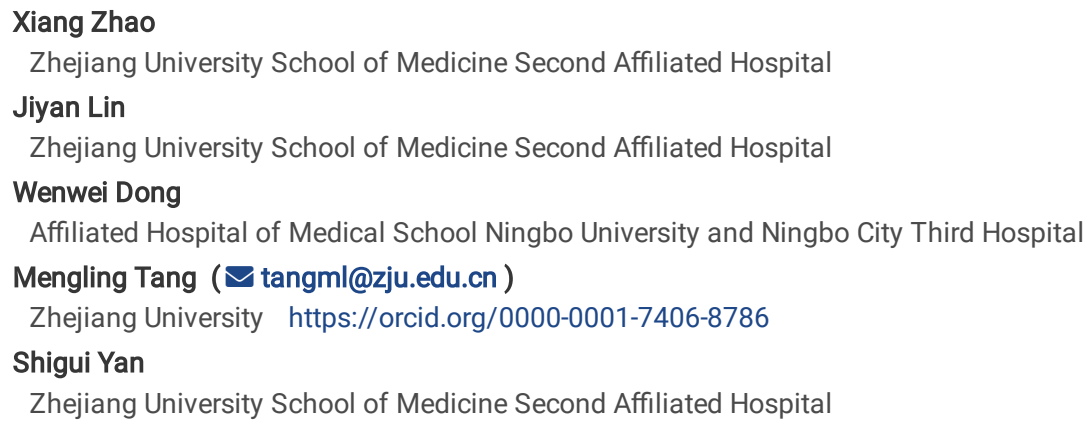

Research

Keywords: osteoporosis, Per- and Polyfluoroalkyl Substances, Bone Mineral Density, NHANES

Posted Date: November 30th, 2021

DOI: https://doi.org/10.21203/rs.3.rs-1086308/v1

License: @ (i) This work is licensed under a Creative Commons Attribution 4.0 International License. Read Full License 


\section{Abstract \\ Background}

Environmental exposures such as perfluoroalkyl substances (PFASs) were considered potential risks for bone mineral density (BMD).

\section{Objective}

To examine the associations between PFASs and BMD among the U.S. population.

\section{Methods}

This study included a total of 6,817 participants from the National Health and Nutrition Examination Survey (NHANES 2005-2014). Multiple linear regression models were used to analyze the associations between serum PFASs and BMD. Covariates such as age, race, BMI, smoking, alcohol intake, milk intake, physical activity, and previous prednisone treatment were adjusted in these models. Additionally, gender and menopausal period were considered in further subgroup analyses.

\section{Results}

Five PFASs (PFOA, PFOS, PFHxS, PFDE and PFNA) with detection rate (DR) higher than $70 \%$ were selected in the analyses of the associations with BMD. Using combined data of NHANES 2005-2014, the effects on BMD were found significant gender differences. Negative associations for PFOA $(\beta=-0.0110 ; 95 \%$ Cl: $-0.0200,-0.0020)$, PFOS ( $\beta=-0.0116 ; 95 \%$ Cl: $-0.0191,-0.0041)$, PFHxS ( $\beta=-0.0081 ; 95 \% \mathrm{Cl}:-0.0140,-0.0021)$ and PFDE ( $\beta=-0.0134 ; 95 \% \mathrm{Cl}:-0.0219,-0.0048)$ were found in premenopausal women, while positive association for $\operatorname{PFOA}(\beta=0.0112 ; 95 \% \mathrm{Cl}: 0.0027,0.0196), \mathrm{PFOS}(\beta=0.0084 ; 95 \% \mathrm{Cl}: 0.0014,0.0153)$, PFHxS( $\beta=0.0063 ; 95 \% \mathrm{Cl}: 0.0003,0.0123), \operatorname{PFDE}(\beta=0.0078 ; 95 \% \mathrm{Cl}: 0.0009,0.0148)$ and PFNA $(\beta=0.0112 ; 95 \% \mathrm{Cl}: 0.0034,0.0190)$ were found in men. In further subgroup analyses, women in pre-menopause statues showed consistent negative associations.

\section{Conclusion}

Serum PFAS concentrations and femur BMD were associated with gender and menopause status differences. Most negative associations were limited to premenopausal women, and most positive associations with femur BMD were found in men. Further epidemiological evidence and studies about the mechanisms are needed.

\section{Introduction}

Osteoporosis is a disease characterized by decreased bone mineral density (BMD), and it is the top bone disorder worldwide. In the U.S., about $10.3 \%$ of people over 50 years have osteoporosis [1]. Many factors in BMD reduction include environment, genes, and individual physiological factors as endogenous levels. The environmental xenoestrogens such as triclosan and polycyclic aromatic hydrocarbons were associated with the level of BMD in previous articles [2, 3].

Per- and polyfluoroalkyl substances (PFASs), including many compounds as perfluorooctane sulfonic acid (PFOS), perfluorooctanoic acid (FPOA), perfluorobutane sulfonic acid (PFBS), perfluorohexane sulfonic acid (PFHxS), perfluononanoic acid (PFNA), perfluorodecanoic acid (PFDE), and 2-(N-MethylFPOSA) acetic acid (MPAH), are chemicals used in a variety of products including food packaging, aqueous film-forming foams, textile coatings, surfactants, and lubricants [4]. Specific perfluorinated precursors can change into stable PFASs by chemical, microbial, and photolytic degradation, and stable PFASs can accumulate in water, atmospheres, and sediment. Because of its bioaccumulative effect, it accumulated in different organisms as fishes [5], frogs [6], birds [7], and mammals [8]. Several studies also found its residue in human bodies. For instance, serum PFOS and PFOA concentrations ranging from 1.70 to 71.50 $\mu \mathrm{g} / \mathrm{L}$ and 0.60 to $9.1 \mu \mathrm{g} / \mathrm{L}$ respectively were found in a Flemish population aged 20 to 40 years [8]. Serum PFNA concentration was reported 3.01(range 2.204.07) $\mu \mathrm{g} / \mathrm{L}$ in children and youth aged 12 to19 old from Quebec [9]. The half-lives of PFOA and PFOS were estimated as long as 3.9 and 3.3 years in the human body, respectively [10].

Due to the extensive usage and residue in the environment, the potential toxicological effects on human health have been taken seriously in recent years. Laboratory animal experiments showed PFASs could cause liver disease [11], tumor [12], reproductive toxicity [7], neurotoxicity [13], and immunotoxicity [14]. Previous studies have reported the associations between PFASs and bone health. Two hundred ninety-four participants in American were measured five major PFASs and found higher plasma PFAS concentrations were associated with a lower BMD [15]. Data from One hundred seventeen subjects aged 18 to 21 years old in Italy showed PFASs exposures were negatively associated with the result of quantitative ultrasound for BMD [16]. Besides, two cross-sectional studies from the U.S. National Health and Nutrition Examination Survey (NHANES 2005-2008 and NHANES 2009-2010) have reported PFAS concentrations were associated with decreased BMD in women $[17,18]$. Further studies with large sample sizes focused on women and considered more critical covariates as menopause were needed.

This study conducted cross-sectional analyses of the association between PFAS constituents, and BMD combined NHANES data from 2005 to 2014. Epidemiological evidence about the associations between PFASs and BMD in the general population were provided, and influential factors as gender and menopause for the associations were considered. 


\section{Material And Methods}

\section{Study population}

Data used in this study came from NHANES 2005 to 2014. NHANES has been in existence since 1960 and has surveyed over 190,000 people. In-home interviews collected variables such as demographic and health-related data, and experienced medical personnel conducted the clinical examination and laboratory results. Previous studies described detailed procedures [17, 18]. The National Center approved the NHANES protocol for Health Statistics Institutional Review Board, and all participants received informed consent.

The framework of the NHANES project designed the methods used to estimate PFAS concentrations and BMD. Participants in NHANES from 2005 to 2014 with both PFAS detection and BMD examination were included in this study, excluding NHANES 2011-2012 for the lack of the BMD data. Besides, participants without neither PFAS nor BMD tests in other year-points were also excluded. The samples for serum PFAS concentrations were from participants aged 12 years and older in NHANES 2005-2010, while from one-third eligible subsamples aged 12 years and older in NHANES 20132014(https://www.cdc.gov/nchs/nhanes/).

\section{Assessment of PFASs and BMD}

NHANES collected a surplus spot serum specimen. Lin and Khalil described the pre-treatment procedure elsewhere [17, 18]. High-Performance Liquid Chromatography-Turbo lon Spray ionization-tandem Mass Spectrometry (HPLC-MS/MS) was used for detection. NHANES tested ten PFASs, including PFOA, PFOS, PFHXS, MPAH, PFDE, PFBS, perfluoroheptanoic acid (PFHP), PFNA, perfluoroundecanoic acid (PFUA), and perflurododecanoic acid (PFDO) in each survey. In NHANES 2013-2014, the different structural isomer patterns of PFOA and PFOS were measured separately. Moreover, the concentrations of PFOA and PFOS were calculated as the sum of different isomer patterns. Samples below the detection limit were assigned a level of LOD (Limit of Detection) divided by the square root of 2 [19]. The detection rate (DR) is the proportion of participants with a value higher than LOD among the total participants who received the tests. We included the ones in this analysis only with the DR higher than $70 \%$.

Trained and certified radiological technologists administered the Dual Energy X-ray Absorptiometry (DXA) examinations. BMD was tested by QDR-4500A fanbeam densitometers (Hologic, Inc., Bedford, Massachusetts) using software version Apex 3.2. The radiation exposure from DXA is shallow at less than $20 \mu \mathrm{Sv}$. Pregnant females were ineligible for the DXA examination. In the current study, BMD was assessed in the proximal femur.

\section{Covariates}

Demographic covariates as age, gender and race/ethnicity, Body Mass Index (BMI), alcohol intake, physical activity, milk intake, previous use of prednisone or cortisone, menopause, vitamin D3 level, previous hip fracture history, and hysterectomy of women were included in this study. Smoking status was determined by serum cotinine level.

Additionally, we marked the participants the different year-points (2005-2006, 2007-2008, 2009-2010, 2013-2014) that they received the survey and set this year-point as another covariate.

\section{Statistical analysis}

Continuous covariates as PFAS concentrations and categorical covariates as gender were expressed as the median (interquartile range) and percent, respectively. For univariate analyses of essential demographic characteristics, Student's two-tailed t-test for standard distribution data, the Wilcox test for nondistribution data, and the chi-square test for count data were used to examine the group between high and low BMD groups (Table 1).

A natural log-transformation of non-normal distribution data was performed before further linear regression analyses. All eligible data were combined (NHANES from 2005 to 2014, excluding 2011-2012 due to the lack of BMD data mentioned earlier) to analyze the associations between PFASs and BMD level. In subgroup analyses, linear regression models were used for the total population, men, and women in menopause, women not in menopause, and each survey. Potential confounders as age, race, BMI, smoking, alcohol intake, milk intake, physical activity, previous prednisone treatment, and year-point were adjusted in multiple linear regression analysis.

\section{Results}

\section{Characteristics of the study population}

A 50,965 population older than 12 years took part in the NHANES surveys (2005-2014). After excluding 25,103 for lack of BMD test and 19,045 for lack of PFAS test, finally, 6,817 participants were included in the final analysis (Figure 1). Among the total population $(n=6,817)$, the majority of the participants were Non-Hispanic white people (44.14\%) and with a low level of physical activity (74.67\%). Subjects who drank accounted for $72.15 \%$, and the median serum cotinine concentration was $0.05(0.02,2.32) \mathrm{ng} / \mathrm{ml}$. The median age of the study population was $45(25,62)$ years and the median BMI was $26.82(23.06$, $31.00) \mathrm{kg} / \mathrm{m} 2$. Detailed information on the population characteristics was given in Table 1.

No difference was found in age, vitamin D3 level, and previous hip fracture history between men and women. Men took more alcohol ( $\mathrm{p}<0.001)$, tobacco $(p<0.001)$, milk $(p<0.001)$, physical activity $(p<0.001)$, and had higher BMI $(p<0.001)$ than women. Women took more prednisone or cortisone than men $(p$ $<0.01)$. Men had higher serum PFAS concentrations than women (Supporting information). 


\section{Pfas Levels And Bmd Distribution}

Five PFASs with the DR higher than 70\% were finally included (99.6\% for PFOA, $99.8 \%$ for PFOS, $97.7 \%$ for PFHxS, 79.8\% for PFDE, and $99.3 \%$ for PFNA). Serum PFAS levels about the whole population were listed in Table 1 (NHANES 2005-2006, 2007-2008, 2009-2010, and 2013-2014). The predominant constituents of PFOS and PFOA account for $82.6 \%$ of the total PFASs with median concentrations of $11.60($ IQR, $6.70-19.10) \mathrm{ng} / \mathrm{mL}$ and 3.40 (IQR, 2.20-5.00) $\mathrm{ng} / \mathrm{mL}$, respectively.

The median value of femur BMD is $0.97(\mathrm{IQR}, 0.86-1.07) \mathrm{g} / \mathrm{cm} 2$. The population was grouped by $\mathrm{BMD}>=0.97$ and $\mathrm{BMD}<0.97$. Femur $\mathrm{BMD}$ was higher in men than in women $(p<0.001)$. Median BMI was higher in the population with higher BMD $(p<0.01)$, whereas age and vitamin D3 levels were higher in the group with lower BMD $(p<0.01)$. The PFOA, PFHxS, and PFNA concentrations were higher in the group with higher BMD levels (Table 3).

\section{Associations Of Pfas And Bmd Levels}

From Table 3, in total population ( $n=6416)$, PFHxS was found positive association with BMD in the crude model $(\beta=0.0071 ; 95 \%$ Cl: $0.0030,0.0111)$, whereas negative association with BMD was found in Model 2 ( $\beta=-0.0052 ; 95 \% \mathrm{Cl}:-0.0091,-0.0015)$. There is no significant association between PFASs and BMD in total women. When divided the women according to the menopause status, for premenopausal women, negative associations between most PFASs and BMD were found, such as PFOS in Model 2 ( $\beta=-0.0110 ; 95 \% \mathrm{Cl}:-0.0200,-0.0020)$, PFOS in Model 1 and Model $2(\beta=-0.0116 ; 95 \%$ Cl: $-0.0191,-0.0041)$, PFHxS in Model 2 ( $\beta=-0.0081 ; 95 \% \mathrm{Cl}:-0.0140,-0.0021)$, and PFDE in Model 1 and Model 2 ( $\beta=-0.0134 ; 95 \% \mathrm{Cl}:-0.0219,-0.0048)$. For menopausal women, only PFHxS was found negatively associated with BMD in the crude model $(\beta=-0.0113 ; 95 \% \mathrm{Cl}:-0.0206,-0.0021)$, whereas PFNA was found positively associated with BMD in the crude model $(\beta=0.0143 ; 95 \% \mathrm{Cl}: 0.0025,0.0260)$.

Different from the results of women, most PFAS were found positive associations with BMD in men. For instance, PFOA ( $\beta=0.0112 ; 95 \%$ Cl: $0.0027,0.0196$; crude model), PFHxS ( $\beta=0.0063 ; 95 \% \mathrm{Cl}: 0.0003,0.0123$; crude model), PFOS ( $\beta=0.0078 ; 95 \% \mathrm{Cl}: 0.0011,0.0144 ;$ model 2$), \mathrm{PFDE}(\beta=0.0078 ; 95 \% \mathrm{Cl}$ : $0.0009,0.0148$; model 3), PFNA ( $\beta=0.0112 ; 95 \% \mathrm{Cl}: 0.0034,0.0190 ;$ model 3) were found positively associated with BMD.

In the survey of $2013-2014$, serum PFOS $(\beta=0.0117 ; 95 \% \mathrm{Cl}: 0.0026,0.0207)$ and PFNA $(\beta=0.0158 ; 95 \%$ Cl: $0.0044,0.0273)$ were found positively associated with femur BMD with all covariates adjusted in total population $(n=986)$.

\section{Discussion}

This cross-sectional study provides evidence that PFAS exposure was associated with BMD based on the combined data of NHANES 2005-2014. Among PFASs detected in NHANES, PFOS and PFOA were prominent constituents in human serum. Gender difference and premenopause status affect the associations between PFASs and BMD significantly.

Gender differences affect the association between PFASs and BMI. Negative associations between serum PFOS exposure and lumbar BMD from NHANES 2005-2008 in premenopausal women was reported [17], and Khalil et al. reported that in the adult population from NHANES 2009-2010, serum PFASs were associated with lower BMD and most associations were limited to women [18]. In Cluett's study from a mid-childhood group [20], the authors also stated more potent effects of PFOA and PFDA concentrations with BMD in girls than boys. Another study from Japan exposed PFOA and PFOS to Japanese medaka and found that the effect patterns were different for each chemical and gender [21]. Our results confirmed their conclusions. Analyses based on the whole survey periods (NHANES 2005-2006, 2006-2007,2009-2010, and 2013-2014) showed negative associations between most PFASs and BMD in women in this study.

Several possible reasons can explain this result. Firstly, PFAS can influence the function of androgen and estrogen. In vitro cell experiment has shown that PFHxS, PFOS, PFOA, PFNA, and PFDA can significantly enhance androgen receptors in a concentration-dependent manner [22]. PFOS and PFOA also enhanced the estrogenic effects in human breast cancer cells [23]. However, sex hormone levels regulated by the HPG axis vary after exposure to PFASs [24] Secondly, the demographic data in our study showed that the concentrations of PFAS in men and women are statistically different. Different PFAS concentrations and different hormone levels may explain the different effects in men and women. Also, the pharmacokinetics of PFASs was reported to be associated with gender differences [25].

Further, the results from our study showed that the association between PFASs and BMD was positive in men. The exact mechanism for this phenomenon is still unclear, and several possible explanations were as follows. Firstly, Di Nisio's study showed PFOA could directly upregulate WNT11 expression, but this effect could be entirely reserved by increased progesterone [16]. WNT11 promoted osteogenic differentiation in mesenchymal stem cells [26]. In premenopausal women, periodicity secreted progesterone guaranteed this reservation effect; in men, the lack of progesterone made this reservation effect deficient. Secondly, a study from NHANES 2007-2008 showed negative associations between FT4 and PFDE, PFHxS, and PFNA. Besides, it also showed positive associations between FT4 and MPAH, PFOA, and PFOS [27]. Theoretically, increased FT4 may inhibit TSH secretion, and low-normal serum THS levels could be a potential risk factor for osteoporosis.

Additionally, in addition to biological effects, PFASs are indicated by their characteristic fluorinated hydrocarbon chain. By creating computational threedimensional molecular models of PFOA, a recent study tested the direct interaction between PFAS and hydroxyapatite [16]. Its result showed a binding affinity within the same range of bisphosphonates, meaning PFAS could act a similar role as bisphosphonates in theory. The latter was widely used for osteoporosis treatment worldwide [28]. Though the authors of the former paper suggested that the affinity of PFAS for hydroxyapatite may directly antagonize the correct assembly of the matrix, we should admit fluorine has been considered a potential therapy for osteoporosis for a long time [29]. A recent study also showed that fluorine suppressed bone resorption by inhibiting osteoclasts' differentiation and function in vitro and in vivo [30]. Another study by Koskela et al. 
measured PFAS concentrations in different bones and showed PFNA with the highest concentration in bones among different PFASs [31]. The toxic effect of PFASs inhibits bone metabolism, and the settled "fluorine" precipitation of PFASs in hydroxyapatite may act like bisphosphonates, thereby increasing the BMD values. Once the latter effect surpasses the former, the tested BMD increase. However, the number of bone samples for the PFAS concentration test in Koskela's study was small, and most of them came from the cadaver. Little is known about the half-life of PFAS in bones, and more researches are needed in the future.

Although the exact mechanism for the association is still uncertain. One previous study reported that PFAS could influence cell signal pathways, activate PPARy, inhibit osteoblast lineage, and potentially reduce bone marrow density [32]. A recent cross-sectional study from Harvard Vanguard Medical Associates by Cluett et al. also supported this finding, which showed PFAS exposure might impair bone accrual in childhood and peak bone mass [33]. Recent studies showed that PFASs could influence fertility by affecting gene expressions [16]. In Nisio's study, they found the up-regulation effect of progesterone on ITGB8, KLF5, SULT1E1, ALPPL2, and G0S2 were antagonized by PFOA. KLF5 was previously found playing roles in bone marrow homing of stem cells [34] and odontoblastic differentiation [35], and Korean women with SULT1E1 genotype was found to have a 4.5\% lower BMD at the distal radius compared to control group [36].

There were several strengths to this study. Firstly, we combined data with a large sample size from 2005 to 2014 to confirm the associations between PFASs and BMD. In subgroup analyses, menopause and gender difference were considered in the study. The association in each survey year of NHANES was analyzed and compared in this study. Some limitations were found in this study. Different associations were found in subgroups with varied PFAS exposure.

Nevertheless, for the limited study about PFAS detection and biological effects, the mechanisms for the associations with BMD were still unclear and cannot be used to support the results of our study. We used BMD in the femur for analysis. When assessing the BMD of a person, one should note that it is possible to have normal BMD in the femur while having osteoporotic BMD levels in the vertebra. Besides, other covariates as sex hormone levels and previous osteoporosis treatment should be considered, and this is a cross-sectional study that cannot provide causal effects from PFAS on BMD. Thus further studies based on prospective study design with more covariates are needed.

In conclusion, based on the NHANES data from the U.S. population, we confirmed the adverse effects of PFASs in premenopausal women reported in previous studies and further found positive associations between certain PFASs (PFNA/PFHxS) and BMD in men. These findings suggest the mechanis

\section{Declarations}

Ethics approval and consent to participate (Human Ethics, Animal Ethics or Plant Ethics): The data in this article come from NHANES. No Ethics approval and consent to participate is needed.

Consent for publication: Not Applicable.

Availability of data and materials: The datasets analysed during the current study are available in NHANES website (https://www.cdc.gov/nchs/nhanes/).

Competing interests: The authors declare that they have no competing interests.

Funding: This study was supported by Natural Science Foundation of Zhejiang Province (LY20H170002).

Authors' contributions[YSG designed the study and reviewed the article. TML and ZX analyzed and interpreted the data, and were major contributors in writing the manuscript. LJY and DWW collect and check the data. All authors read and approved the final manuscript.

Acknowledgments: Special appreciation should be given to the NHANES team and the participants in it.

Disclosure Summary: The authors have nothing to disclose.

\section{References}

1. French ZP, Caird MS, Whitney DG: Osteoporosis Epidemiology Among Adults With Cerebral Palsy: Findings From Private and Public Administrative Claims Data. JBMR Plus 2019, 3(11):e10231.

2. Guo J, Huang Y, Bian S, Zhao C, Jin Y, Yu D, Wu X, Zhang D, Cao W, Jing F et al: Associations of urinary polycyclic aromatic hydrocarbons with bone mass density and osteoporosis in U.S. adults, NHANES 2005-2010. ENVIRON POLLUT 2018, 240:209-218.

3. Cai S, Zhu J, Sun L, Fan C, Zhong Y, Shen Q, Li Y: Association Between Urinary Triclosan With Bone Mass Density and Osteoporosis in US Adult Women, 20052010. J Clin Endocrinol Metab 2019, 104(10):4531-4538.

4. O'Carroll DM, Jeffries TC, Lee MJ, Le ST, Yeung A, Wallace S, Battye N, Patch DJ, Manefield MJ, Weber KP: Developing a roadmap to determine per- and polyfluoroalkyl substances-microbial population interactions. SCI TOTAL ENVIRON2020, 712:135994

5. Suominen K, Hallikainen A, Ruokojarvi P, Airaksinen R, Koponen J, Rannikko R, Kiviranta H: Occurrence of PCDD/F, PCB, PBDE, PFAS, and organotin compounds in fish meal, fish oil and fish feed. CHEMOSPHERE 2011, 85(3):300-306.

6. Flynn RW, Chislock MF, Gannon ME, Bauer SJ, Tornabene BJ, Hoverman JT, Sepulveda MS: Acute and chronic effects of perfluoroalkyl substance mixtures on larval American bullfrogs (Rana catesbeiana). CHEMOSPHERE 2019, 236:124350.

7. Dennis NM, Karnjanapiboonwong A, Subbiah S, Rewerts JN, Field JA, McCarthy C, Salice CJ, Anderson TA: Chronic Reproductive Toxicity of Perfluorooctane Sulfonic Acid and a Simple Mixture of Perfluorooctane Sulfonic Acid and Perfluorohexane Sulfonic Acid to Northern Bobwhite Quail 
(Colinus virginianus). ENVIRON TOXICOL CHEM 2020, 39(5):1101-1111.

8. Fernandez-Sanjuan M, Faria M, Lacorte S, Barata C: Bioaccumulation and effects of perfluorinated compounds (PFCs) in zebra mussels (Dreissena polymorpha). Environ Sci Pollut Res Int 2013, 20(4):2661-2669.

9. Caron-Beaudoin E, Ayotte P, Laouan SE, Gros-Louis MN, Lemire M: Exposure to perfluoroalkyl substances (PFAS) and associations with thyroid parameters in First Nation children and youth from Quebec. ENVIRON INT 2019, 128:13-23.

10. Worley RR, Moore SM, Tierney BC, Ye X, Calafat AM, Campbell S, Woudneh MB, Fisher J: Per- and polyfluoroalkyl substances in human serum and urine samples from a residentially exposed community. ENVIRON INT 2017, 106:135-143.

11. Bassler J, Ducatman A, Elliott M, Wen S, Wahlang B, Barnett J, Cave MC: Environmental perfluoroalkyl acid exposures are associated with liver disease characterized by apoptosis and altered serum adipocytokines. ENVIRON POLLUT 2019, 247:1055-1063.

12. Jacquet N, Maire MA, Rast C, Bonnard M, Vasseur P: Perfluorooctanoic acid (PFOA) acts as a tumor promoter on Syrian hamster embryo (SHE) cells. Environ Sci Pollut Res Int 2011, 19(7):2537-2549.

13. Sammi SR, Foguth RM, Nieves CS, De Perre C, Wipf P, McMurray CT, Lee LS, Cannon JR: Perfluorooctane Sulfonate (PFOS) Produces Dopaminergic Neuropathology in Caenorhabditis elegans. TOXICOL SCI 2019, 172(2):417-434.

14. Zarei MH, Hosseini SS, Aghvami M, Pourahmad J: Perfluorooctanesulfonate (PFOS) Induces Apoptosis Signaling and Proteolysis in Human Lymphocytes through ROS Mediated Mitochondrial Dysfunction and Lysosomal Membrane Labialization. IRAN J PHARM RES 2018, 17(3):995-1007.

15. Hu Y, Liu G, Rood J, Liang L, Bray GA, de Jonge L, Coull B, Furtado JD, Qi L, Grandjean P et al: Perfluoroalkyl substances and changes in bone mineral density: A prospective analysis in the POUNDS-LOST study. ENVIRON RES 2019, 179(Pt A):108775.

16. Di Nisio A, De Rocco PM, Giadone A, Rocca MS, Guidolin D, Foresta C: Perfluoroalkyl substances and bone health in young men: a pilot study. ENDOCRINE 2020, 67(3):678-684.

17. Lin LY, Wen LL, Su TC, Chen PC, Lin CY: Negative association between serum perfluorooctane sulfate concentration and bone mineral density in US premenopausal women: NHANES, 2005-2008. J Clin Endocrinol Metab 2014, 99(6):2173-2180.

18. Khalil N, Chen A, Lee M, Czerwinski SA, Ebert JR, DeWitt JC, Kannan K: Association of Perfluoroalkyl Substances, Bone Mineral Density, and Osteoporosis in the U.S. Population in NHANES 2009-2010. Environ Health Perspect 2016, 124(1):81-87.

19. Calafat AM, Wong LY, Kuklenyik Z, Reidy JA, Needham LL: Polyfluoroalkyl chemicals in the U.S. population: data from the National Health and Nutrition Examination Survey (NHANES) 2003-2004 and comparisons with NHANES 1999-2000. Environ Health Perspect 2007, 115(11):1596-1602.

20. Cluett R, Seshasayee SM, Rokoff LB, Rifas-Shiman SL, Ye X, Calafat AM, Gold DR, Coull B, Gordon CM, Rosen CJ et al: Per-and Polyfluoroalkyl Substance Plasma Concentrations and Bone Mineral Density in Midchildhood: A Cross-Sectional Study (Project Viva, United States). Environ Health Perspect 2019, 127(8):87006.

21. Kang JS, Ahn TG, Park JW: Perfluorooctanoic acid (PFOA) and perfluooctane sulfonate (PFOS) induce different modes of action in reproduction to Japanese medaka (Oryzias latipes). J HAZARD MATER 2019, 368:97-103.

22. Behr AC, Lichtenstein D, Braeuning A, Lampen A, Buhrke T: Perfluoroalkylated substances (PFAS) affect neither estrogen and androgen receptor activity nor steroidogenesis in human cells in vitro. TOXICOL LETT 2018, 291:51-60.

23. Pierozan P, Cattani D, Karlsson O: Perfluorooctane sulfonate (PFOS) and perfluorooctanoic acid (PFOA) induce epigenetic alterations and promote human breast cell carcinogenesis in vitro. ARCH TOXICOL 2020, 94(11):3893-3906.

24. Zhang L, Meng Z, Chen L, Zhang G, Zhang W, Tian Z, Wang Z, Yu S, Zhou Z, Diao J: Perfluorooctanoic acid exposure impact a trade-off between selfmaintenance and reproduction in lizards (Eremias argus) in a gender-dependent manner. ENVIRON POLLUT 2020, 262:114341.

25. Kim SJ, Heo SH, Lee DS, Hwang IG, Lee YB, Cho HY: Gender differences in pharmacokinetics and tissue distribution of 3 perfluoroalkyl and polyfluoroalkyl substances in rats. FOOD CHEM TOXICOL 2016, 97:243-255.

26. Zhu JH, Liao YP, Li FS, Hu Y, Li Q, Ma Y, Wang H, Zhou Y, He BC, Su YX: Wnt11 promotes BMP9-induced osteogenic differentiation through BMPs/Smads and p38 MAPK in mesenchymal stem cells. J CELL BIOCHEM 2018, 119(11):9462-9473.

27. Jain RB: Association between thyroid profile and perfluoroalkyl acids: data from NHNAES 2007-2008. ENVIRON RES 2013, 126:51-59.

28. Black DM, Rosen CJ: Clinical Practice. Postmenopausal Osteoporosis. N Engl J Med 2016, 374(3):254-262.

29. Jesserer H: [Fluorine therapy of osteoporosis]. Hippokrates 1974, 45(3):354-365.

30. Liu S, Zhou H, Liu H, Ji H, Fei W, Luo E: Fluorine-contained hydroxyapatite suppresses bone resorption through inhibiting osteoclasts differentiation and function in vitro and in vivo. Cell Prolif 2019, 52(3):e12613.

31. Koskela A, Koponen J, Lehenkari P, Viluksela M, Korkalainen M, Tuukkanen J: Perfluoroalkyl substances in human bone: concentrations in bones and effects on bone cell differentiation. Sci Rep 2017, 7(1):6841.

32. Yamamoto J, Yamane T, Oishi Y, Kobayashi-Hattori K: Perfluorooctanoic acid binds to peroxisome proliferator-activated receptor gamma and promotes adipocyte differentiation in 3T3-L1 adipocytes. Biosci Biotechnol Biochem 2015, 79(4):636-639.

33. Cluett R, Seshasayee SM, Rokoff LB, Rifas-Shiman SL, Ye X, Calafat AM, Gold DR, Coull B, Gordon CM, Rosen CJ et al: Per-and Polyfluoroalkyl Substance Plasma Concentrations and Bone Mineral Density in Midchildhood: A Cross-Sectional Study (Project Viva, United States). Environ Health Perspect 2019, 127(8):87006.

34. Taniguchi IE, Chang KH, Nayak R, Olsson HA, Ficker AM, Dunn SK, Madhu MN, Sengupta A, Whitsett JA, Grimes HL et al: Klf5 controls bone marrow homing of stem cells and progenitors through Rab5-mediated beta1/beta2-integrin trafficking. NAT COMMUN 2013, 4:1660. 
35. Chen Z, Zhang Q, Wang H, Li W, Wang F, Wan C, Deng S, Chen H, Yin Y, Li X et al: Klf5 Mediates Odontoblastic Differentiation through Regulating DentinSpecific Extracellular Matrix Gene Expression during Mouse Tooth Development. Sci Rep 2017, 7:46746.

36. Lee SA, Choi JY, Shin CS, Hong YC, Chung H, Kang D: SULT1E1 genetic polymorphisms modified the association between phytoestrogen consumption and bone mineral density in healthy Korean women. Calcif Tissue Int 2006, 79(3):152-159.

\section{Tables}

Table 1 Characteristics of NHANES 2005-2006, 2007-2008, 2009-2010 and 2013-2014 study participants

\begin{tabular}{|c|c|c|c|c|c|c|c|c|}
\hline & & \multicolumn{2}{|c|}{ Total population } & \multicolumn{2}{|c|}{$\mathrm{BMD}>=0.965 \mathrm{~g} / \mathrm{cm}^{2}$} & \multicolumn{2}{|c|}{$\mathrm{BMD}<0.965 \mathrm{~g} / \mathrm{cm}^{2}$} & \multirow{2}{*}{$\begin{array}{l}\mathrm{p} \\
\text { value }\end{array}$} \\
\hline \multicolumn{2}{|l|}{ Characteristic variable } & $\mathrm{n}$ & $\begin{array}{l}\text { Median(IQ range) or } \\
\text { percent }\end{array}$ & $\mathrm{n}$ & $\begin{array}{l}\text { Median(IQ range) or } \\
\text { percent }\end{array}$ & $\mathrm{n}$ & $\begin{array}{l}\text { Median(IQ range) } \\
\text { or percent }\end{array}$ & \\
\hline \multicolumn{2}{|l|}{ Age(years) } & 6817 & $45(24,62)$ & 3411 & $41(23,55)$ & 3406 & $52(26,67)$ & $<0.01$ \\
\hline \multirow[t]{2}{*}{ Gender } & Male & 3470 & $50.90 \%$ & 2220 & $65.08 \%$ & 1250 & $36.70 \%$ & \multirow[t]{2}{*}{$<0.01$} \\
\hline & Female & 3347 & $49.10 \%$ & 1191 & $34.92 \%$ & 2156 & $63.30 \%$ & \\
\hline \multirow[t]{5}{*}{ Race/ethnicity } & $\begin{array}{l}\text { Mexican } \\
\text { American }\end{array}$ & 1360 & $19.95 \%$ & 691 & $20.26 \%$ & 669 & $19.64 \%$ & \multirow[t]{5}{*}{$<0.0$} \\
\hline & Other Hispanic & 607 & $8.90 \%$ & 306 & $8.97 \%$ & 301 & $8.84 \%$ & \\
\hline & $\begin{array}{l}\text { Non-hispanic } \\
\text { white }\end{array}$ & 3009 & $44.14 \%$ & 1334 & $39.11 \%$ & 1675 & $49.18 \%$ & \\
\hline & $\begin{array}{l}\text { Non-hispanic } \\
\text { Black }\end{array}$ & 1428 & $20.95 \%$ & 934 & $27.38 \%$ & 494 & $14.50 \%$ & \\
\hline & Other race & 413 & $6.06 \%$ & 146 & $4.28 \%$ & 267 & $7.84 \%$ & \\
\hline \multicolumn{2}{|l|}{$\mathrm{BMI}\left(\mathrm{kg} / \mathrm{m}^{2}\right)$} & 6783 & $26.82 \rrbracket 23.06 \rrbracket 31.00 \rrbracket$ & 3392 & $28.50 \rrbracket 24.97 \rrbracket 32.53 \rrbracket$ & 3391 & $25.06(21.68,28.97)$ & $<0.01$ \\
\hline \multicolumn{2}{|l|}{ Smoking status(cotinine level) } & 6491 & $0.05(0.02,2.32)$ & 3252 & $0.07(0.02,5.65)$ & 3239 & $0.04(0.02,1.01)$ & 0.85 \\
\hline \multicolumn{2}{|l|}{ Vitamin D3(nmol/L) } & 6264 & $57.10(41.27,73.70)$ & 3183 & $57.40(43.00,71.40)$ & 3081 & $56.80(39.40,74.70)$ & $<0.01$ \\
\hline \multirow[t]{2}{*}{12 alcohol drinks $/ 1$ year? } & Yes & 3747 & $72.15 \%$ & 2020 & $78.29 \%$ & 1727 & $66.09 \%$ & \multirow[t]{2}{*}{$<0.01$} \\
\hline & No & 1446 & $27.85 \%$ & 560 & $21.71 \%$ & 886 & $33.91 \%$ & \\
\hline \multirow{2}{*}{$\begin{array}{l}\text { Regular milk use } 5 \text { times per } \\
\text { week }\end{array}$} & Yes & 2338 & $64.23 \%$ & 1215 & $67.20 \%$ & 1123 & $61.30 \%$ & \multirow[t]{2}{*}{$<0.01$} \\
\hline & No & 1302 & $35.77 \%$ & 593 & $32.80 \%$ & 709 & $28.70 \%$ & \\
\hline \multirow[t]{2}{*}{ vigorous-intensity activity } & Yes & 1702 & $25.23 \%$ & 1007 & $29.73 \%$ & 695 & $20.70 \%$ & \multirow[t]{2}{*}{$<0.01$} \\
\hline & No & 5043 & $74.67 \%$ & 2380 & $70.27 \%$ & 2663 & $79.30 \%$ & \\
\hline \multirow{2}{*}{$\begin{array}{l}\text { previous use of predinisone or } \\
\text { cortisone }\end{array}$} & Yes & 275 & $5.06 \%$ & 115 & $4.27 \%$ & 160 & $5.84 \%$ & \multirow[t]{2}{*}{0.01} \\
\hline & No & 5159 & $94.94 \%$ & 2577 & $95.73 \%$ & 2582 & $94.16 \%$ & \\
\hline \multirow[t]{2}{*}{ Previous hip fracture } & Yes & 84 & $1.54 \%$ & 26 & $0.96 \%$ & 58 & $2.10 \%$ & \multirow[t]{2}{*}{$<0.01$} \\
\hline & No & 5382 & $98.46 \%$ & 2682 & $99.04 \%$ & 2700 & $97.90 \%$ & \\
\hline \multicolumn{2}{|l|}{$\operatorname{PFOA}(\mathrm{ng} / \mathrm{ml})^{\mathrm{a}}$} & 6416 & $3.40(2.20,5.00)$ & 3226 & $3.50(2.30,5.10)$ & 3190 & $3.30(2.18,4.80)$ & $<0.01$ \\
\hline \multicolumn{2}{|l|}{ PFOS(ng/ml) ${ }^{a}$} & 6416 & $11.60(6.70,19.10)$ & 3226 & $11.65(6.80,19.30)$ & 3190 & $11.50(6.50,18.70)$ & 0.07 \\
\hline \multicolumn{2}{|l|}{$\operatorname{PFHxS}(\mathrm{ng} / \mathrm{ml})^{\mathrm{a}}$} & 6416 & $1.80(1.00,3.10)$ & 3226 & $1.90(1.00,3.30)$ & 3190 & $1.70(1.00,3.00)$ & $<0.01$ \\
\hline \multicolumn{2}{|l|}{$\operatorname{PFDE}(\mathrm{ng} / \mathrm{ml})^{\mathrm{a}}$} & 6416 & $0.30(0.20,0.40)$ & 3226 & $0.30(0.20,0.40)$ & 3190 & $0.30(0.14,0.40)$ & 0.13 \\
\hline \multicolumn{2}{|l|}{$\operatorname{PFNA}(\mathrm{ng} / \mathrm{ml})^{\mathrm{a}}$} & 6416 & $1.07(0.74,1.60)$ & 3226 & $1.10(0.80,1.64)$ & 3190 & $1.07(0.70,1.56)$ & $<0.01$ \\
\hline
\end{tabular}

as serum sample for all participants(NHANES 2005-2006,2007-2008,2009-2010, and 2013-2014). SD: standard deviation; IQ range: interquartile range.

The median value of BMD is $0.965 \mathrm{~g} / \mathrm{cm}^{2}$.

Table 2 Adjusted Regression Coefficients(95\% Cls) for Changes in Total Hip BMD Relative to a Unite Increase in Natural PFAS Concentrastions, with restults weighted for sampling strategy(NHANES 2013-2014) 


\begin{tabular}{|c|c|c|c|c|c|c|c|c|}
\hline \multirow{4}{*}{$\begin{array}{l}\text { Short } \\
\text { chain } \\
\text { name }\end{array}$} & \multirow{4}{*}{$\begin{array}{l}\text { Sample } \\
\text { detection } \\
\text { rate }\end{array}$} & & \multicolumn{6}{|l|}{ Total hip BMD $₫ \mathrm{~g} / \mathrm{cm} 2$} \\
\hline & & & \multirow{2}{*}{\multicolumn{2}{|c|}{ Total }} & \multirow{2}{*}{\multicolumn{2}{|c|}{ Men }} & \multicolumn{2}{|l|}{ Women } \\
\hline & & & & & & & \multicolumn{2}{|l|}{ Not in Menopause/hysterectomy } \\
\hline & & & $95 \% \mathrm{CI}$ & $\mathrm{n}$ & $95 \% \mathrm{CI}$ & $\mathrm{n}$ & $95 \% \mathrm{CI}$ & $\mathrm{n}$ \\
\hline \multirow[t]{3}{*}{ PFOA } & $99.2 \%$ & $\begin{array}{l}\text { Model } \\
1\end{array}$ & $-0.0044(-0.0181,0.0094)$ & 986 & $0.0095(-0.0103,0.0293)$ & 472 & $-0.0402(-0.0612,-0.0191)^{c}$ & 299 \\
\hline & & $\begin{array}{l}\text { Model } \\
2\end{array}$ & $-0.0017(-0.0143,0.0109)$ & 986 & $0.0136(-0.0061,0.0332)$ & 472 & $-0.0181(-0.0383,0.0020)$ & 299 \\
\hline & & $\begin{array}{l}\text { Model } \\
3\end{array}$ & $0.0017(-0.0099,0.0133)$ & 918 & $0.0116(-0.0072,0.0304)$ & 444 & $-0.0105(-0.0292,0.0083)$ & 259 \\
\hline \multirow[t]{3}{*}{ PFOS } & $99.1 \%$ & $\begin{array}{l}\text { Model } \\
1\end{array}$ & $0.0080(-0.0024,0.0183)$ & 986 & $0.0144(0.0002,0.0286)^{a}$ & 472 & $-0.0221(-0.0387,-0.0054)^{b}$ & 299 \\
\hline & & $\begin{array}{l}\text { Model } \\
2\end{array}$ & $0.0097(-0.0002,0.0195)$ & 986 & $0.0215(0.0071,0.0359)^{b}$ & 472 & $-0.0002(-0.0163,0.0160)$ & 299 \\
\hline & & $\begin{array}{l}\text { Model } \\
3\end{array}$ & $0.0117(0.0026,0.0207)^{a}$ & 918 & $0.0212(0.0075,0.0350)^{b}$ & 444 & $0.0037(-0.0117,0.0191)$ & 259 \\
\hline \multirow[t]{3}{*}{ PFHxS } & $91.1 \%$ & $\begin{array}{l}\text { Model } \\
1\end{array}$ & $0.0054(-0.0053,0.0161)$ & 986 & $0.0195(0.0036,0.0353)^{a}$ & 472 & $-0.0371(-0.0544,-0.0197)^{c}$ & 299 \\
\hline & & $\begin{array}{l}\text { Model } \\
2\end{array}$ & $0.0021(-0.0082,0.0125)$ & 986 & $0.0225(0.0068,0.0383)^{b}$ & 472 & $-0.0111(-0.0289,0.0066)$ & 299 \\
\hline & & $\begin{array}{l}\text { Model } \\
3\end{array}$ & $0.0060(-0.0035,0.0154)$ & 918 & $0.238(0.0089,0.0387)^{b}$ & 444 & $-0.0091(-0.0260,0.0078)$ & 259 \\
\hline \multirow[t]{3}{*}{ PFNA } & $90.6 \%$ & $\begin{array}{l}\text { Model } \\
1\end{array}$ & $0.0084(-0.0053,0.0220)$ & 986 & $0.0187(0.0003,0.0372)^{a}$ & 472 & $-0.0261(-0.0478,-0.0044)^{a}$ & 299 \\
\hline & & $\begin{array}{l}\text { Model } \\
2\end{array}$ & $0.0115(-0.0009,0.0240)$ & 986 & $0.0234(0.0049,0.0420)^{a}$ & 472 & $-0.0034(-0.0240,0.0173)$ & 299 \\
\hline & & $\begin{array}{l}\text { Model } \\
3\end{array}$ & $0.0158(0.0044,0.0273)^{b}$ & 918 & $0.0265(0.0088,0.0443)^{b}$ & 444 & $-0.0021(-0.0214,0.0173)$ & 259 \\
\hline
\end{tabular}

Log transformed serum PFASs concentrations were used for analysis. Model 1 had no adjustment. Model 2 adjusted for age, race/ethnicity. Model 3 adjusted for model 2 plus BMI, smoking, alcohol intake, milk intake, physical activity, and previous prednisone treatment. Additionally, for the total people group, sex was also used as a covariate for Model 2 and Model 3.

${ }^{a} p<0.05,{ }^{b} p<0.01,{ }^{c} p<0.001$ 
Table 3

Adjusted Regression Coefficients(95\% Cls) for Changes in Total Hip BMD Relative to a Unite Increase in Natural Long chain PFAS Concentrastions, with re: sampling strategy(NHANES 2005-2006,2007-2008,2009-2010,and 2013-2014).

\begin{tabular}{|c|c|c|c|c|c|c|c|c|c|}
\hline \multirow{4}{*}{$\begin{array}{l}\text { Long } \\
\text { chain } \\
\text { name }\end{array}$} & \multirow{4}{*}{$\begin{array}{l}\text { Detection } \\
\text { rate }\end{array}$} & & \multicolumn{7}{|l|}{ Total hip BMD, g/cm2 } \\
\hline & & & \multicolumn{2}{|l|}{ Total } & \multicolumn{2}{|l|}{ Men } & \multicolumn{3}{|l|}{ Women } \\
\hline & & & \multirow[b]{2}{*}{$95 \% \mathrm{Cl}$} & \multirow[b]{2}{*}{$\mathrm{n}$} & \multirow[b]{2}{*}{$95 \% \mathrm{Cl}$} & \multirow[b]{2}{*}{$\mathrm{n}$} & \multicolumn{2}{|c|}{ Not in Menopause/hysterectomy } & \multirow{2}{*}{$\begin{array}{l}\text { In Menopaus } \\
95 \% \mathrm{Cl}\end{array}$} \\
\hline & & & & & & & $95 \% \mathrm{Cl}$ & $\mathrm{n}$ & \\
\hline \multirow[t]{3}{*}{ PFOA } & \multirow[t]{3}{*}{$99.6 \%$} & $\begin{array}{l}\text { Model } \\
1\end{array}$ & $0.0112(0.0054,0.0171)^{c}$ & 6416 & $0.0112(0.0027,0.0196)^{b}$ & 3275 & $-0.0075(-0.0165,0.0015)$ & 1963 & $0.0024(-0.01$ \\
\hline & & $\begin{array}{l}\text { Model } \\
2\end{array}$ & $-0.0042(-0.0096,0.0013)$ & 6416 & $0.0089(0.0005,0.0173)^{a}$ & 3275 & $-0.0110(-0.0200,-0.0020)^{a}$ & 1963 & $0.0065(-0.00$ \\
\hline & & $\begin{array}{l}\text { Model } \\
3\end{array}$ & $-0.0020(-0.0074,0.0035)$ & 4947 & $0.0024(-0.0060,0.0108)$ & 2518 & $-0.0019(-0.0114,0.0075)$ & 1154 & $0.0096(-0.00$ \\
\hline \multirow[t]{3}{*}{ PFOS } & \multirow[t]{3}{*}{$99.8 \%$} & $\begin{array}{l}\text { Model } \\
1\end{array}$ & $0.0063(0.0016,0.0109)^{b}$ & 6416 & $0.0041(-0.0025,0.0107)$ & 3275 & $-0.0083(-0.0158,-0.0008)^{a}$ & 1963 & $-0.0042(-0.01$ \\
\hline & & $\begin{array}{l}\text { Model } \\
2\end{array}$ & $-0.0031(-0.0075,0.0014)$ & 6416 & $0.0078(0.0011,0.0144)^{a}$ & 3275 & $-0.0116(-0.0191,-0.0041)^{b}$ & 1963 & $0.0028(-0.00$ \\
\hline & & $\begin{array}{l}\text { Model } \\
3\end{array}$ & $0.0014(-0.0034,0.0061)$ & 4947 & $0.0084(0.0014,0.0153)^{a}$ & 2518 & $-0.0046(-0.0132,0.0041)$ & 1154 & $0.0056(-0.00$ \\
\hline \multirow[t]{3}{*}{ PFHxS } & \multirow[t]{3}{*}{$97.7 \%$} & $\begin{array}{l}\text { Model } \\
1\end{array}$ & $0.0071(0.0030,0.0111)^{\mathrm{c}}$ & 6416 & $0.0063(0.0003,0.0123)^{a}$ & 3275 & $-0.0059(-0.0118,0.0001)$ & 1963 & $-0.0113(-0.0$; \\
\hline & & $\begin{array}{l}\text { Model } \\
2\end{array}$ & $-0.0052(-0.0091,-0.0015)^{b}$ & 6416 & $0.0052(-0.0007,0.0111)$ & 3275 & $-0.0081(-0.0140,-0.0021)^{b}$ & 1963 & $0.0012(-0.00$ \\
\hline & & $\begin{array}{l}\text { Model } \\
3\end{array}$ & $-0.0025(-0.0065,0.0014)$ & 4947 & $0.0050(-0.0011,0.0111)$ & 2518 & $-0.0059(-0.0127,0.0009)$ & 1154 & $0.0057(-0.00$ \\
\hline \multirow[t]{3}{*}{ PFDE } & \multirow[t]{3}{*}{$79.8 \%$} & $\begin{array}{l}\text { Model } \\
1\end{array}$ & $0.0028(-0.0026,0.0081)$ & 6416 & $0.0043(-0.0028,0.0116)$ & 3275 & $-0.0123(-0.0201,-0.0038)^{b}$ & 1963 & $0.0077(-0.00$ \\
\hline & & $\begin{array}{l}\text { Model } \\
2\end{array}$ & $-0.0009(-0.0059,0.0040)$ & 6416 & $0.0049(-0.0023,0.0121)$ & 3275 & $-0.0134(-0.0219,-0.0048)^{b}$ & 1963 & $0.0031(-0.00$ \\
\hline & & $\begin{array}{l}\text { Model } \\
3\end{array}$ & $0.0037(-0.0011,0.0085)$ & 4947 & $0.0078(0.0009,0.0148)^{a}$ & 2518 & $-0.0033(-0.0126,0.0060)$ & 1154 & $0.0042(-0.00$ \\
\hline \multirow[t]{3}{*}{ PFNA } & \multirow[t]{3}{*}{$99.3 \%$} & $\begin{array}{l}\text { Model } \\
1\end{array}$ & $0.0129(0.0070,0.0188)^{c}$ & 6416 & $0.0151(0.0070,0.0233)^{c}$ & 3275 & $-0.0037(-0.0132,0.0057)$ & 1963 & $0.0143(0.00$; \\
\hline & & $\begin{array}{l}\text { Model } \\
2\end{array}$ & $0.0051(-0.0004,0.0105)$ & 6416 & $0.0142(0.0061,0.0223)^{c}$ & 3275 & $-0.0047(-0.0141,0.0047)$ & 1963 & $0.0099(-0.00$ \\
\hline & & $\begin{array}{l}\text { Model } \\
3\end{array}$ & $0.0054(0.0002,0.0106)^{a}$ & 4947 & $0.0112(0.0034,0.0190)^{b}$ & 2518 & $0.0022(-0.0076,0.0120)$ & 1154 & $0.0078(-0.00$ \\
\hline
\end{tabular}

Log transformed serum PFASs concentrations were used for analysis. Model 1 had no adjustment. Model 2 adjusted for age, race/ethnicity. Model 3 adjuste BMl, smoking, alcohol intake, milk intake, physical activity, previous prednisone treatment, and the years participants received examinations(2005-2006,2007 and 2013-2014). Additionally, for the total people group, sex was also used as a covariate for Model 2 and Model 3.

${ }^{a} p<0.05,{ }^{b} p<0.01,{ }^{c} p<0.001$

\section{Figures}




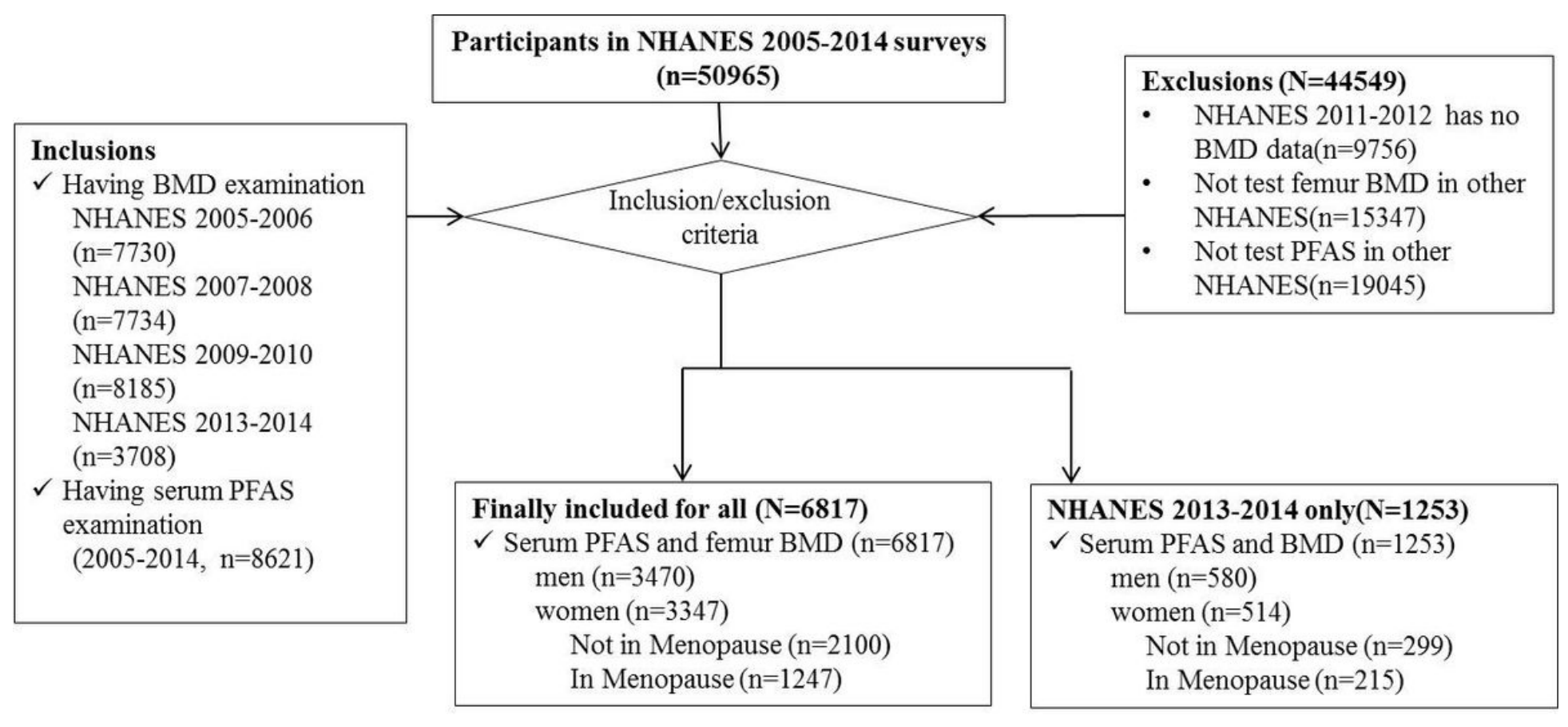

Figure 1

The process of data screening. 